Check for updates

Cite this: RSC Adv., 2020, 10, 9704

Received 1st November 2019

Accepted 20th February 2020

DOI: 10.1039/c9ra09045b

rsc.li/rsc-advances

\title{
Interaction of cellulose and nitrodopamine coated superparamagnetic iron oxide nanoparticles with alpha-lactalbumin $\uparrow$
}

\author{
Fakhrossadat Mohammadi, (DD *a Marzieh Moeeni, ${ }^{\text {a }}$ Chengnan Li, ${ }^{\text {b }}$ \\ Rabah Boukherroub ${ }^{b}$ and Sabine Szunerits (iD *b
}

\begin{abstract}
In recent years, numerous studies have focused on the understanding of the interactions between proteins and nanoparticles (NPs). In this work, we focus on the interaction of bovine $\alpha$-lactalbumin (BLA) with differently coated magnetic nanoparticles (MP): as formed MP, MPs stabilized with dopamine $\left(\mathrm{MP}_{\text {dopamine }}\right)$ and nanoparticles coated with cellulose $\left(\mathrm{MP}_{\text {cellulose}}\right)$. The influence of the coating on the nanoparticle-protein interaction is revealed by a set of different experiments. The binding affinity $\left(K_{\mathrm{A}}\right)$ between BLA and these three structures was found to vary from $10^{5} \mathrm{M}^{-1}$ (for MPs) to $10^{11} \mathrm{M}^{-1}$ $\left(\mathrm{MP}_{\text {cellulose }}\right)$. The orientation of BLA and the involvement of amino acid residues in the process of interaction with magnetic nanoparticles were identified by molecular docking studies. In addition, circular dichroism spectra revealed that the conformation of BLA was conserved upon interaction with the magnetic nanoparticles.
\end{abstract}

\section{Introduction}

The increased use of nanomaterials for biomedical applications necessitates an improved understanding of their behavior in biological environments. This is particularly relevant as upon injection of nanostructures into the bloodstream, nanomaterials interact with different serum proteins resulting in the formation of protein corona (PC). The structure of protein corona is a highly dynamic process with its composition changing over time and being protein dependent. ${ }^{1}$ Most importantly, the decoration of nanomaterials with proteins endows them with new properties which can significantly affect their biological pathways. The physicochemical properties of nanoparticles, including material composition, size, shape, surface charge, surface functionalization etc. have to be taken into account in the understanding of protein corona formation. $^{2}$ A study by Tenzer et al. revealed that the rapid human plasma corona formation on silica and polystyrene NPs of various size and surface functionalization significantly affected nanoparticle uptake. ${ }^{3}$ Li et al. demonstrated further that protein interactions with nanoscale materials can disrupt their native

${ }^{a}$ Department of Chemistry, Institute for Advanced Studies in Basic Sciences (IASBS), 444 Prof. Sobouti Blvd., Gava Zang, Zanjan 45137-66731, Iran. E-mail: fmohammadi@iasbs.ac.ir; Fax: +98-24-33153232; Tel: +98-24-33153218

${ }^{b}$ Univ. Lille, CNRS, Centrale Lille, ISEN, Univ. Valenciennes, UMR 8520-IEMN, F59000 Lille, France. E-mail: sabine.szunerits@univ-lille1.fr; Fax: +33 3625317 01; Tel: +33 362531725

† Electronic supplementary information (ESI) available. See DOI: 10.1039/c9ra09045b conformation and compromise their biological activity. ${ }^{4}$ Paul et al. investigated the interaction of magnetic ferro fluid with bovine serum albumin. They report the key role of electrostatic interaction in the process of binding and the domain I of BSA determined as a favorable binding site. ${ }^{5}$ Wang et al. reported the reversibility and thermostability of polyethyleneimine coated silver nano particles with the two protein homologs (lysozyme and alpha lactalbumin). ${ }^{6}$ Carnovale et al. reported the impact of nanogold morphology on the interaction with human serum albumin. ${ }^{7}$

Most of these considerations are also valid for superparamagnetic iron oxide nanoparticles (SPIONs), which are widely used for biomedical applications. ${ }^{\mathbf{8 - 1 4}}$ Hofman and coworkers investigated in this respect the effect of surface charge and coating materials of MPs on the final composition of the formed protein corona. ${ }^{\mathbf{1 4}}$ No correlation between protein charge and nanoparticle surface charge on protein binding was observed, nor a direct correlation between the serum proteins' concentration and the proteins present.

In this work, we opted for investigating further the influence of surface coating of MPs on the interaction with bovine $\alpha$ lactalbumin (BLA), a large complex of several $\alpha$-lactalbumin molecules. BLA is a major component of milk proteins and possesses immunologic defense as well as antitumor and bactericidal activities. This small protein $(14.2 \mathrm{kDa})$, homologues to the lysozyme family in sequence, stabilizes itself against the action of temperature and various denaturing factors upon binding the calcium cation $\left(\mathrm{Ca}^{2+}\right)$. BLA has also been widely used as a model system as its high surface hydrophobicity has shown to be a key factor in modulating protein- 
nanoparticle interactions. ${ }^{\mathbf{1 5 , 1 6}}$ Indeed, the magnetic nature of MPs and the capability of removing them upon the application of a magnetic field make these nanocarriers of high interest for biomedical applications. One of the major roles of milk proteins such as BLA is the transport of the drugs/bioactive compounds and facilitating their functionality in delivery system. By understanding the physico-chemical properties of BLA-MP corona and its stability in vivo experiments the new nanoplatform will be designed which has the potent drug binding ability because of the binding sites on BLA further more to its antibacterial and anti-tumor effects. Lystvet et al. reported that the immobilization onto gold nanoparticles makes alphalactalbumin interaction with pure and mixed phospholipid monolayers stronger compared to the native protein. This increased bioinvasiveness of protein - nanoconstructs is potentially applicable within protein based drugs and drug delivery, as well as of fundamental interest within nanotoxicology. ${ }^{17}$

In this work, we show that in contrast to uncoated magnetic particles (MPs) and nitrodopamine stabilized ones ( $\left.\mathrm{MP}_{\text {dopamine }}\right)$, cellulose coated magnetic nanoparticles $\left(\mathrm{MP}_{\text {cellulose }}\right)$ show high affinity for $\alpha$-lactalbumin with a $K_{\mathrm{A}}=$ to $10^{11} \mathrm{M}^{-1}$. The secondary structure of BLA remains unchanged upon interaction with $\mathrm{MP}_{\text {cellulose }}$ Docking studies were performed and identified tryptophan residues, especially Trp118, to be in closest contact with $\mathrm{MP}_{\text {cellulose }}$.

\section{Experimental section}

\subsection{Materials}

$\alpha$-Lactalbumin (BLA), iron(II) chloride tetrahydrate $\left(\mathrm{FeCl}_{2} \cdot 4 \mathrm{H}_{2}\right.$ $\mathrm{O})$, iron(III) chloride hexahydrate $\left(\mathrm{FeCl}_{3} \cdot 6 \mathrm{H}_{2} \mathrm{O}\right)$, dopamine hydrochloride, ammonium hydroxide $\left(\mathrm{NH}_{4} \mathrm{OH}\right)$ and cellulose were purchased from Sigma-Aldrich and used as received. Dulbecco's Modified Eagle's medium (DMEM, Gibco®) supplemented with $10 \%$ fetal bovine serum (FBS, Gibco ${ }^{\circledR}$ ) and 1\% penicillin-streptomycin (Gibcoß) were purchased from Fisher Scientific. 2-Nitrodopamine was synthesized as reported previously. ${ }^{18}$

\subsection{Synthesis of different $\mathrm{Fe}_{3} \mathrm{O}_{4}$ nanoparticle}

2.2.1 Synthesis of $\mathrm{Fe}_{3} \mathrm{O}_{4}$ nanoparticle (MP). In this work, magnetic particles (MP) were prepared as reported previously. ${ }^{19}$ $\mathrm{FeCl}_{2} \cdot 4 \mathrm{H}_{2} \mathrm{O}(0.34 \mathrm{~g}, 1.7 \mathrm{mmol})$ and $\mathrm{FeCl}_{3} \cdot 6 \mathrm{H}_{2} \mathrm{O}(0.95 \mathrm{~g}, 3.5$ $\mathrm{mmol})$ were dissolved in deaerated water $(20 \mathrm{~mL})$. This mixture was subsequently added to a nitrogen-protected three-necked flask under sonication. The resulting mixture was heated at $50{ }^{\circ} \mathrm{C}$ for $30 \mathrm{~min}$. Then concentrated ammonium hydroxide (2 $\mathrm{mL}$ ) was added dropwise and kept at constant temperature (50 ${ }^{\circ} \mathrm{C}$ ) for $30 \mathrm{~min}$. The system was finally cooled to room temperature and the solid product was isolated via a non-uniform magnetic field generated by a $\mathrm{Nd}-\mathrm{Fe}-\mathrm{B}$ permanent magnet. The resulting $\mathrm{Fe}_{3} \mathrm{O}_{4}$ particles were washed six times with Milli-Q water to remove unreacted chemicals and then stored in water. They were lyophilized at the end of synthesis process.
2.2.2 Synthesis of 2-nitrodopamine and cellulose coated

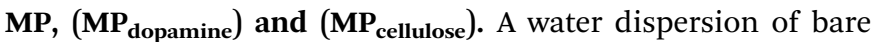
MP (10 mg mL $\mathrm{mL}^{-1}, 1 \mathrm{~mL}$ ) was mixed with 2-nitrodopamine (or cellulose) (10 mg) and sonicated for $1 \mathrm{~h}$ at room temperature. ${ }^{19}$ The nitrodopamine and cellulose modified MPs were isolated by a $\mathrm{Nd}-\mathrm{Fe}-\mathrm{B}$ permanent magnet and purified through six consecutive wash/precipitation cycles with water to ensure complete removal of unreacted 2-nitrodopamine or cellulose. The precipitate was dried in an oven at $50{ }^{\circ} \mathrm{C}$.

\subsection{Characterization}

2.3.1 Transmission electron microscopy (TEM). Transmission electron microscopy analysis of the prepared samples was carried out by using a FEI, TECNAI G2 F20 instrument operated at an accelerated voltage of $300 \mathrm{kV}\left(C_{\mathrm{s}}=0.6 \mathrm{~mm}\right.$, resolution $1.7 \AA$ ). For the TEM analysis, the sample was prepared by drop casting $10 \mu \mathrm{L}$ of the dispersed solution of $1 \mathrm{mg}$ material in $5 \mathrm{~mL}$ isopropyl alcohol over a carbon coated 200 mesh $\mathrm{Cu}$ grid. The nanoparticles drop casted $\mathrm{Cu}$ grid was dried and the prepared sample was used for the imaging purpose.

2.3.2 Magnetic properties. Magnetic properties were determined using a MPMS-XL SQUID magnetometer. The magnetization loops $M(H)$ were measured at $300 \mathrm{~K}$ by sweeping the applied magnetic field between 20 kOe and -20 kOe. Thermal variation of magnetization was measured using the zero-field-cooled (ZFC) procedure, for which the sample is first cooled down to $5 \mathrm{~K}$ in absence of applied magnetic field, and then magnetization is measured during the warming of the sample up to $400 \mathrm{~K}$, with an applied magnetic field of 80 Oe.

2.3.3 UV/Vis measurements. Absorption spectra were recorded using SAFAS UV/Vis spectrophotometer (Société Anonyme de Fabrication d'Appareillages Scientifiques, Monaco) in quartz cuvettes with an optical path of $10 \mathrm{~mm}$. The wavelength range was $200-1100 \mathrm{~nm}$.

2.3.4 Zeta-potential measurements. Zeta potential measurements were carried out by Zetasizer Nano-ZS (Malvern Instruments Inc. Worcestershire, UK). Nanomaterials were diluted to $1 \mathrm{nM}$ and measured in Milli-Q water and transferred to disposable folded capillary zeta cell for zeta potential measurement.

\subsection{Fluorescence spectroscopy}

The intrinsic fluorescence spectra of BLA were recorded by Varian Cary Eclipse fluorescence spectrophotometer. The excitation wavelength was set at $280 \mathrm{~nm}$ and the emission spectra were recorded in the range of 300-450 $\mathrm{nm}$ using $10 \mathrm{~mm}$ quartz cells. The width of the excitation and emission slits was adjusted at $5 \mathrm{~nm} .1 \mathrm{~mL}$ of $2.5 \mu \mathrm{M}$ BLA was titrated sequentially by addition of magnetic particle solutions using a micropipet. The simultaneously scan of the excitation and emission monochromators was done for recording the synchronous fluorescence spectra. The wavelength interval $\left(\Delta \lambda=\lambda_{\mathrm{em}}-\lambda_{\mathrm{ex}}\right)$ was fixed individually at 15 and $60 \mathrm{~nm}$, at which the characteristic information of tyrosine and tryptophan residues were obtained, respectively. The Trp fluorescence intensity of the solution containing $2.5 \mu \mathrm{m}$ BLA and $1 \mathrm{mg} \mathrm{mL}{ }^{-1}$ magnetic 
particle was recorded after increasing the $5-20 \mathrm{mM}$ of $\mathrm{NaCl}$ at the excitation wavelength of $295 \mathrm{~nm}$. For FRET investigation, emission and absorption spectrum of the solution containing $1.5 \mu \mathrm{M}$ protein and $400 \mu \mathrm{L}$ magnetic particle $\left(0.5 \mathrm{mg} \mathrm{mL}^{-1}\right)$ was recorded.

\subsection{Circular dichroism spectroscopy}

Aviv spectropolarimeter model 215 (proterion Corp., USA) was used for recording the circular dichroism spectra by using $1 \mathrm{~mm}$ path length cell. In the far-UV region (190-260) the alteration in the secondary structure of the protein in the absence and presence of magnetic nanoparticles can be investigated. CDNN software, as an artificial intelligence program based on the neural network, was used to estimate the secondary structure content of the protein. The results were expressed in molar ellipticity (deg $\mathrm{cm}^{2} \mathrm{dmol}^{-1}$ ).

\subsection{Fourier transform infrared (FTIR)}

FTIR spectra were recorded using a ThermoScientific FTIR instrument (Nicolet 8700 ) in the $550-4000 \mathrm{~cm}^{-1}$ range at a spectral resolution of $6 \mathrm{~cm}^{-1} .1 \mathrm{mg}$ of dried sample was mixed with $200 \mathrm{mg}$ of $\mathrm{KBr}$ powder in an agar mortar. The mixture was pressed into a pellet under 7 tons of load for 2-4 min, and the spectrum was recorded immediately. A total of 64 accumulative scans were collected. The signal from a pure $\mathrm{KBr}$ pellet was subtracted as a background.

\subsection{X-ray photoelectron spectroscopy (XPS)}

XPS was recorded using ESCALAB 220 XL spectrometer from Vacuum Generators featuring a monochromatic Al $\mathrm{K} \alpha$ X-ray source $(1486.6 \mathrm{eV})$ and a spherical energy analyzer operated in the CAE (constant analyzer energy) mode (CAE $=100 \mathrm{eV}$ for survey spectra and $\mathrm{CAE}=40 \mathrm{eV}$ for high-resolution spectra), using the electromagnetic lens mode. The angle between the incident X-rays and the analyzer is $58^{\circ}$ and the detection angle of the photoelectrons is $30^{\circ}$. For XPS analysis, a small drop $(\sim 20$ $\mu \mathrm{L}$ ) of the final product was placed onto a clean titanium coated substrate and allowed to dry in a vacuum desiccator. This step was repeated until a complete layer of MPs was formed on the substrate and the substrate Ti signal was minimized during XPS analysis. The samples were stored in Petri-dishes backfilled with nitrogen gas and wrapped with parafilm.

\subsection{Theoretical investigation}

Molecular docking was carried out using software Hex.8.8. Hex is an interactive molecular graphics program for calculating and displaying possible docking modes of protein. Ligands and protein were introduced to system, in PDB format. The crystal structure of BLA was downloaded from the website of protein data bank (PDB). As the size of protein is significantly smaller than nanoparticles, we assume all types of magnetic nanoparticle as a large crystalline surface. For that purpose, one layered comprising 1044 atoms each was built from the Gauss View software and the charge on the nanoparticles was kept zero. $^{\mathbf{2 0 , 2 1}}$ For instruction of the cellulose/nitrodopamine coated
MP, the cellulose/nitrodopamine molecules were covered on the surface of $\mathrm{Fe}_{3} \mathrm{O}_{4}$ lattice by Discovery studio visualizer (DSV). The resultant capped structure of magnetic nanoparticles was then saved in PDB format for using in molecular docking simulations. Hex performs protein docking using Spherical Polar Fourier Correlations. The parameters used for docking include: correlation type - shape only, FFT mode - 3D, grid dimension 0.6 , receptor range -180 , ligand range -180 , twist range -360 , distance range - 40. Discovery studio visualizer (DSV) was used for visualizing the docked structures. ${ }^{\mathbf{2 0 2 1}}$ Hex sorts the generated orientation by docking energy and prints a summary of the 10000 highest scoring (lowest energy) orientations. The best 500 orientations are retained for viewing. The distances between bound ligands and the tryptophan residues were calculated with PyMol method.

\subsection{Cell viability assay}

The NG108-15 cell line, formed by fusing mouse N18TG2 neuroblastoma cells with rat C6-BU-1 glioma cells [ATCC® HB-12317 тм , ECACC, Sigma Aldrich, Saint-Quentin Fallavier, France], was cultured and maintained in Dulbecco's Modified Eagle's medium (DMEM, Gibco®) supplemented with $10 \%$ fetal bovine serum (FBS, Gibco ${ }^{\circledR}$ ) and 1\% penicillin-streptomycin (Gibco $囚$ ) in a humidified incubator at $37{ }^{\circ} \mathrm{C}$ and $5 \%$ $\mathrm{CO}_{2}$. Cells were seeded at a density of $10^{4}$ cells per well in a 96well plate and grown for $24 \mathrm{~h}$ before assay. The culture medium was replaced with a fresh medium that contains magnetic nanoparticles from 0 to $200 \mu \mathrm{g} \mathrm{mL}{ }^{-1}$. After $24 \mathrm{~h}$, the old medium was aspirated and cells were washed with PBS. The cell viability was evaluated using a resazurin cell viability assay. Briefly, $100 \mu \mathrm{L}$ of the resazurin solution $\left(11 \mu \mathrm{g} \mathrm{mL}^{-1}\right)$ in DMEM/10\% FBS were added to each well and the plate was incubated for $4 \mathrm{~h}$ in the humidified incubator. The fluorescence emission of each well was measured at $593 \mathrm{~nm}(20 \mathrm{~nm}$ bandwidth) with an excitation at $554 \mathrm{~nm}$ (18 nm bandwidth) using a Cytation ${ }^{\mathrm{TM}} 5$ Cell Imaging Multi-Mode Reader (BioTek Instruments SAS, France). Each condition was replicated three times and the mean fluorescence value of non-exposed cells was taken as $100 \%$ cellular viability.

\section{Results and discussion}

\subsection{Fabrication and characterization of different magnetic nanoparticles}

Magnetic particles can be prepared by a set of different approaches including the co-precipitation reaction, flame spray pyrolysis, solvothermal/hydrothermal synthesis, microemulsion and high-thermal decomposition. ${ }^{22-25}$ The precipitation process, due to its simplicity, is one of the most widely employed route for the synthesis of MPs. The main advantages of this approach is the possibility to produce a large amount of material in a short time with a good control over shape and particle size $(2-50 \mathrm{~nm})$ by adjusting the $\mathrm{pH}$, ionic strength and concentration of the growth solution. 2-Nitrodopamine ${ }^{19}$ and cellulose coated magnetic nanoparticles ${ }^{26}$ were produced in a two-step process. First, naked magnetic particles (MP) were 
(A)

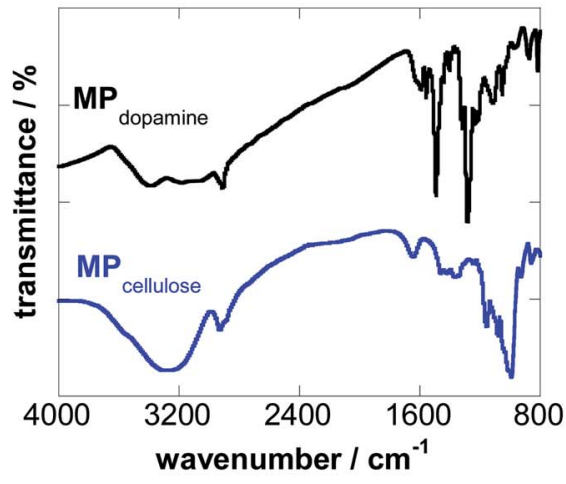

wavenumber $/ \mathrm{cm}^{-1}$

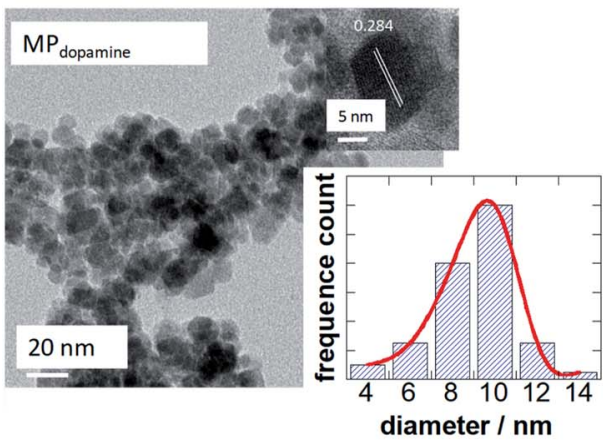

(B)

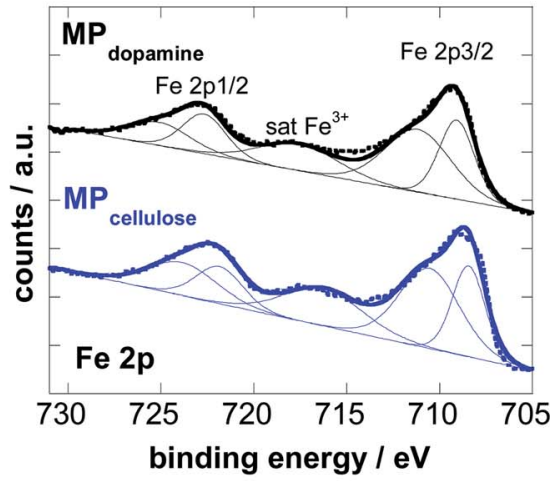

(C)

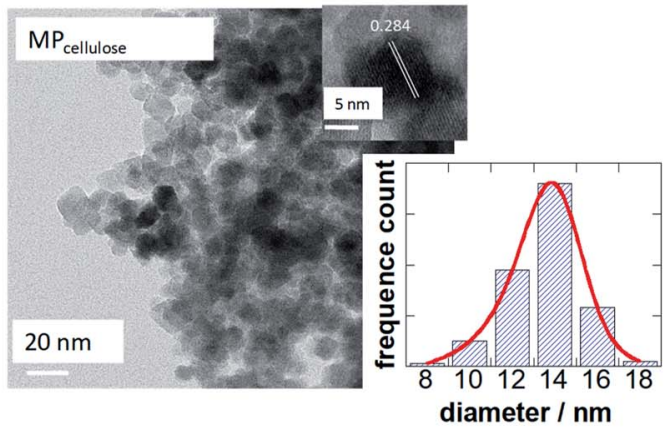

(D)

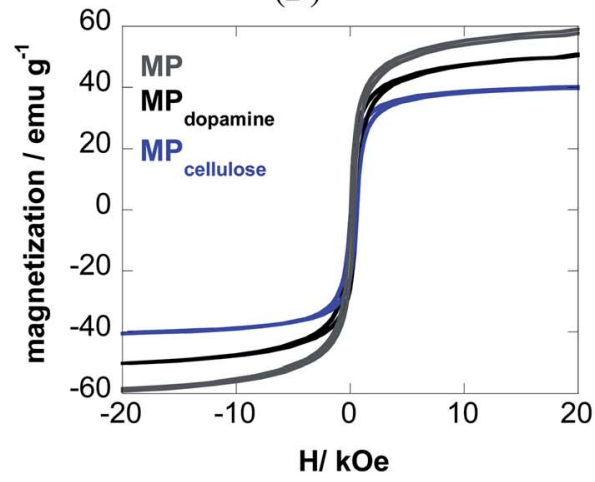

Fig. 1 Characterization of 2-nitrodopamine and cellulose coated magnetic particles: (A) FTIR spectra; (B) Fe 2p high resolution XPS spectra; (C) Transmission electron microscopy (TEM) and HRTEM analysis, (D) zero-field-cooled (ZFC) magnetization curves with an applied field of 80 Oe and hysteresis curves at $300 \mathrm{~K}$ for naked MP (grey), MP dopamine (black) and MP cellulose (blue).

prepared by the co-precipitation reaction of $\mathrm{Fe}^{2+}$ and $\mathrm{Fe}^{3+}$ in alkaline medium. These particles were post-coated with 2nitrodopamine as well as cellulose, a hydrophilic polysaccharide, consisting of a linear chain of $\beta(1 \rightarrow 4)$ linked $D^{-}$ glucose units. 2-Nitrodopamine is considered an ideal ligand to stabilize magnetic particles binding irreversible to the magnetic nanostructures. In the case of cellulose, the multiple hydroxyl groups of cellulose interact strongly with the formed magnetic particles forming a stable nanocomposite.

The success of coating of MP with 2-nitrodopamine and cellulose was confirmed by FTIR (Fig. 1A) and XPS analysis (Fig. 1B). The FTIR spectrum of MP dopamine shows bands at 2882 and $2920 \mathrm{~cm}^{-1}$ (CH stretching vibrations of the dopamine ligand), $\approx 1290 \mathrm{~cm}^{-1}\left(\mathrm{C}-\mathrm{O}\right.$ or $\mathrm{NO}_{2}$ vibration), and $1500 \mathrm{~cm}^{-1}$
( $\mathrm{C}=\mathrm{C}$ vibration of the catechol system), which overlap with the asymmetric vibrations of $\mathrm{NO}_{2}$ at about $1548 \mathrm{~cm}^{-1}$. The broad band at $3367 \mathrm{~cm}^{-1}$ and the band at $1650 \mathrm{~cm}^{-1}$ are ascribed to the stretching and bending mode of the primary amines of the dopamine ligand. The FTIR spectrum of $\mathrm{MP}_{\text {cellulose }}$ show a large broad band centered at $\approx 3400 \mathrm{~cm}^{-1}(\mathrm{OH}$ stretching of

Table 1 Physico-chemical characteristics of the magnetic particles

\begin{tabular}{lcccccc}
\hline Particles & C 1s & O 1s & N 1s & Fe 2p & Zeta potential/mV & Size/nm \\
\hline MP $_{\text {dopamine }}$ & 24.2 & 59.3 & 3.3 & 13.2 & $+20.2 \pm 2.5$ & $8 \pm 2$ \\
MP $_{\text {cellulose }}$ & 19.6 & 65.3 & - & 15.2 & $-22.9 \pm 2.3$ & $14 \pm 3$
\end{tabular}


cellulose), as well as bands at $2929 \mathrm{~cm}^{-1}$ (C-H stretching), $1623 \mathrm{~cm}^{-1}$ (OH bending) and $1152 \mathrm{~cm}^{-1}$ (C-O-C stretching).

The survey XPS spectra of both particles show contributions of Fe 2 p, O 1s, C 1s and N 1s in accordance with the chemical composition of the particles (Table 1). The density of the $\mathrm{NH}_{2}$ groups incorporated onto $\mathrm{MP}_{\text {dopamine }}$ was determined using the Kaiser test, ${ }^{27}$ and was estimated to be $41 \pm 11 \mathrm{nM} \mathrm{g}^{-1}$, in accordance with other amino-functional magnetic particles. ${ }^{28}$

From the Fe 2p core level XPS spectra (Fig. 1B), the bands at 709.0 and $711.0 \mathrm{eV}$ indicate the presence of both $\mathrm{Fe}^{2+}$ and $\mathrm{Fe}^{3+}$ species, with satellite peak at $\approx 717 \mathrm{eV}$ being a direct evidence for the presence of $\mathrm{Fe}^{3+}$ in the form of $\gamma-\mathrm{Fe}_{2} \mathrm{O}_{3}$, due to a partial oxidation of the coated magnetic particles. The degree of oxidation is comparable for both particles.

From transmission electron microscopy (TEM) images, the size of the $\mathrm{MP}_{\text {dopamine }}$ and $\mathrm{MP}_{\text {cellulose }}$ particles was estimated being $8 \pm 2$ and $14 \pm 3 \mathrm{~nm}$ in diameter, respectively (Fig. 1C). The HRTEM analysis of the particles underlines the crystalline nature of the particle with a fringe width of $0.284 \mathrm{~nm}$ corresponding to $\mathrm{Fe}_{3} \mathrm{O}_{4}$ nanoparticles.
(A)
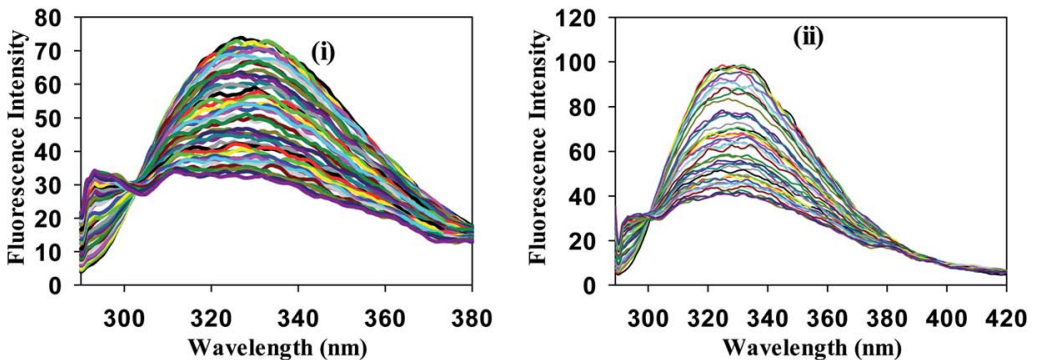

(B)
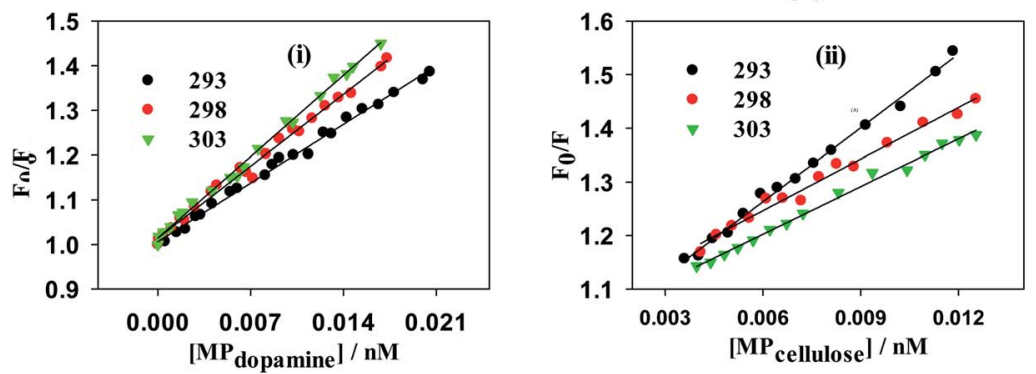

(C)
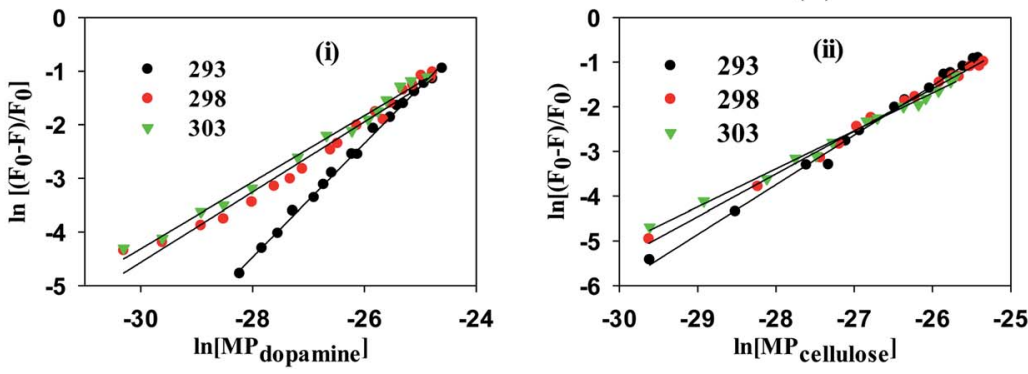
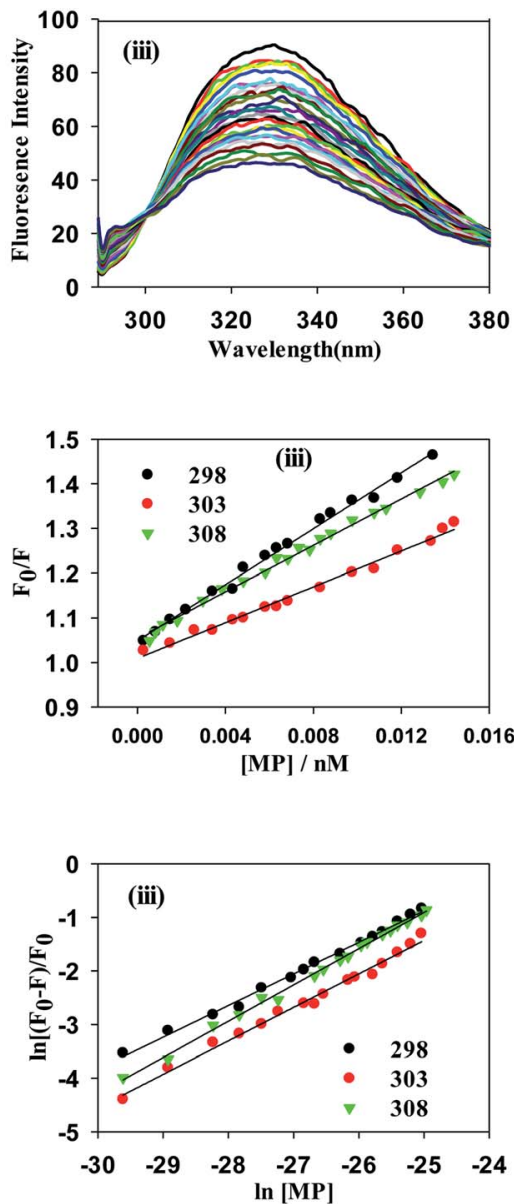

(D)
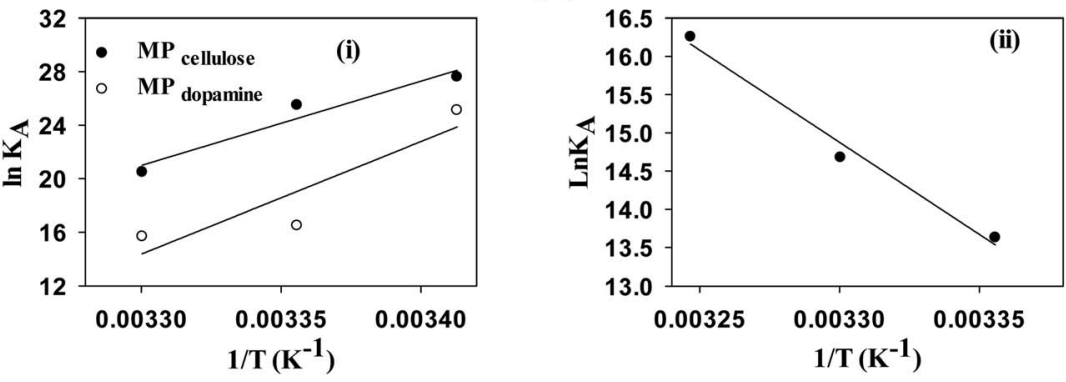

Fig. 2 Determination of interaction strength between BLA and different magnetic particles: MP, MPdopamine, $M P_{\text {cellulose: }}(A)$ fluorescence quenching of $\mathrm{BLA}(2.5 \mu \mathrm{M})$ by (i) $\mathrm{MP}_{\text {dopamine, }}$ (ii) $\mathrm{MP}_{\text {cellulose }}$ and (iii) naked magnetic particles (MP) upon excitation at $\lambda_{\text {ex }}=280 \mathrm{~nm}$ in the absence and presence of increasing concentration of particles $(0-0.015 \mathrm{nM})$; (B) the Stern-Volmer plots for (i) $M P_{\text {dopamine, }}$ (ii) $M P_{\text {cellulose }}$ and (iii) naked magnetic particles at different temperatures; (C) plots of $\ln \left(F_{0}-F / F\right)$ versus [particles] of BLA quenched by (i) $M P_{\text {dopamine, }}$ (ii) $M P_{\text {cellulose }}$ and (iii) magnetic particles; (D) van't Hoff plot for (i) $\mathrm{MP}_{\text {dopamine }}$ and $\mathrm{MP}_{\text {cellulose, }}$ (ii) naked magnetic particles. 
Table 2 Change in Stern-Volmer quenching constant $\left(K_{\mathrm{Sv}}\right)$, bimolecular quenching rate constant $\left(k_{\mathrm{q}}\right)$, the number of binding sites $n$, and binding constant $\left(K_{\mathrm{A}}\right)$ between magnetic particles and $\mathrm{BLA}=2.5 \mu \mathrm{M}$ at different temperatures

\begin{tabular}{llllll}
\hline Particle & $T / \mathrm{K}$ & $K_{\mathrm{SV}} / \mathrm{M}^{-1}$ & $k_{\mathrm{q}} / \mathrm{M}^{-1} \mathrm{~s}^{-1}$ & $n$ & $K_{\mathrm{A}} / \mathrm{M}^{-1}$ \\
\hline MP $_{\text {cellulose }}$ & 293 & $(4.50 \pm 0.04) \times 10^{10}$ & $(4.50 \pm 0.04) \times 10^{19}$ & $1.12 \pm 0.02$ & $(9.68 \pm 5.01) \times 10^{11}$ \\
& 298 & $(3.64 \pm 0.07) \times 10^{10}$ & $(3.64 \pm 0.07) \times 10^{19}$ & $1.04 \pm 0.02$ & $(1.18 \pm 0.70) \times 10^{11}$ \\
& 303 & $(3.60 \pm 0.06) \times 10^{10}$ & $(3.60 \pm 0.06) \times 10^{19}$ & $0.85 \pm 0.02$ & $(7.91 \pm 3.62) \times 10^{8}$ \\
MP $_{\text {dopamine }}$ & 293 & $(1.84 \pm 0.03) \times 10^{10}$ & $(1.84 \pm 0.03) \times 10^{19}$ & $1.05 \pm 0.02$ & $(8.03 \pm 4.39) \times 10^{10}$ \\
& 298 & $(2.29 \pm 0.02) \times 10^{10}$ & $(2.29 \pm 0.02) \times 10^{19}$ & $0.70 \pm 0.02$ & $(1.43 \pm 0.73) \times 10^{7}$ \\
MP & 303 & $(2.62 \pm 0.03) \times 10^{10}$ & $(2.62 \pm 0.03) \times 10^{19}$ & $0.67 \pm 0.02$ & $(6.41 \pm 3.80) \times 10^{6}$ \\
& 298 & $(3.01 \pm 0.07) \times 10^{10}$ & $(3.01 \pm 0.07) \times 10^{19}$ & $0.58 \pm 0.02$ & $(8.29 \pm 3.81) \times 10^{5}$ \\
& 303 & $(1.97 \pm 0.05) \times 10^{10}$ & $(1.97 \pm 0.05) \times 10^{19}$ & $0.64 \pm 0.03$ & $(2.01 \pm 1.50) \times 10^{6}$ \\
& 308 & $(2.71 \pm 0.07) \times 10^{10}$ & $(2.71 \pm 0.07) \times 10^{19}$ & $0.69 \pm 0.01$ & $(1.14 \pm 3.33) \times 10^{7}$
\end{tabular}

Table 3 Binding constants of different proteins to magnetic nanostructures

\begin{tabular}{|c|c|c|c|}
\hline Protein & MP & $K_{\mathrm{A}} / \mathrm{M}^{-1}$ & Ref. \\
\hline Bovine serum albumin & $\mathrm{Fe}_{3} \mathrm{O}_{4}$ nanoparticles stabilized by SDBS & $2.40 \times 10^{8}$ & 30 \\
\hline Immunoglobulin & $\mathrm{Fe}_{3} \mathrm{O}_{4}$ nanoparticles stabilized by PEG & $2.61 \times 10^{6}$ & 13 \\
\hline
\end{tabular}

From the $M(H)$ loops (Fig. 1D) the magnetization at $20 \mathrm{kOe}$ is determined as $60 \mathrm{emu}^{-1}$ for uncoated MP lower than the saturation value $\left(M_{\mathrm{s}}\right)$ reported for bulk $\mathrm{Fe}_{3} \mathrm{O}_{4}\left(\approx 92 \mathrm{emu} \mathrm{g}^{-1}\right)$, resulting from the small particle size and large surface-tovolume ratio and other surface effects. Saturation of magnetization is obtained in the case of $\mathrm{MP}_{\text {dopamine }}$ and $\mathrm{MP}_{\text {cellulose }}$ particles, with a saturation magnetization value of 42 and 8 emu $\mathrm{g}^{-1}$, respectively. This reduced saturation value is related to the mass of the coating layer and possibly, the electron exchange between the surface Fe atoms and the ligands of the polymer.

\subsection{Binding affinity of magnetic particles with BLA}

The $\mathrm{MP}_{\text {cellulose }}$ and $\mathrm{MP}$ are negatively charged $\left(\zeta_{\mathrm{MP}_{\text {cellulose }}}=\right.$ $-22.9 \mathrm{mV}, \zeta_{\mathrm{MP}}=-22.5 \mathrm{mV}$ ). Upon incubation of $1 \mathrm{nM}$ $\mathrm{MP}_{\text {cellulose }}$ and MP particles for $150 \mathrm{~min}$ in $5 \mu \mathrm{M}$ BLA the zeta potential shifted to $\zeta=-32.2 \mathrm{mV}$ due to the existence of highly negatively charged BLA on the MP and MP $\mathrm{P}_{\text {cellulose }}$ surface, the first evidence for the interaction of BLA with the particles. Also the positive surface charge of $\mathrm{MP}_{\text {dopamine }}$ alters to negative charge $(\zeta=-22.9 \mathrm{mV}$ ) which confirms the firmly stick of negative BLA on the surface of $\mathrm{MP}_{\text {dopamine }}$ particle.

To gain a better understanding on the nature and strength of the interaction taking place between BLA and the magnetic nanostructures, steady-state fluorescence measurements were performed. ${ }^{20}$ BLA contains four tryptophan residues which are responsible for its intrinsic fluorescence with tyrosine and phenylalanine units contributing in addition to the fluorescence signal. Upon excitation at $280 \mathrm{~nm}$, BLA displays an emission at $338 \mathrm{~nm}$, which is quenched in the presence of increasing concentrations of $\mathrm{MP}, \mathrm{MP}_{\text {dopamine }}$ and $\mathrm{MP}_{\text {cellulose }}$ (Fig. 2A). Analysis of the fluorescence data using the SternVolmer equation,

$$
\frac{F_{0}}{F}=1+K_{\mathrm{SV}}[\mathrm{MP}]=1+k_{\mathrm{q}} \tau_{0}[\mathrm{MP}]
$$

where $F_{0}$ and $F$ are the fluorescence intensities in the absence and presence of particles, $K_{\mathrm{SV}}$ the Stern-Volmer quenching constant, $k_{\mathrm{q}}$ the bimolecular quenching rate constant, and $\tau_{0}$ the average lifetime of the biomolecule without the quencher, respectively, allows determination of the binding constant $K_{\mathrm{A}}$ between BLA and the magnetic particle using eqn (2) with $n$ being the Hill coefficient.

$$
\ln \left(\frac{F_{0}-F}{F}\right)=\ln K_{\mathrm{A}}+n \ln [\mathrm{MP}]
$$

From a plot of $F_{0} / F$ versus [MP] (Fig. 2B), the Stern-Volmer constant can be determined from the slope (Table 2). The value of $K_{\mathrm{SV}}$ is decreasing for $\mathrm{MP}_{\text {cellulose }}$, while increasing for

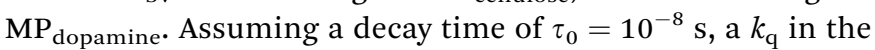
order of $10^{19} \mathrm{M}^{-1} \mathrm{~s}^{-1}$ is obtained which is greater than the diffusion-controlled quenching value of $10^{10} \mathrm{M}^{-1} \mathrm{~s}^{-1} .^{29}$ This confirms that the quenching initiated with $\mathrm{MP}, \mathrm{MP}_{\text {dopamine }}$ and $\mathrm{MP}_{\text {cellulose }}$ is not diffusion controlled and the result of binding interaction between BLA with the magnetic nanostructures. A plot of $\ln \left(F_{0}-F / F\right)$ (eqn (2)) (Fig. 2C) allowed the

Table 4 Thermodynamic parameters of the interaction of magnetic nanoparticles with BLA $(2.5 \mu \mathrm{M})$ at $298 \mathrm{~K}$

\begin{tabular}{lrrr}
\hline Particle & $\Delta H^{\circ} / \mathrm{kJ} \mathrm{mol}^{-1}$ & $\Delta S^{\circ} / \mathrm{J} \mathrm{mol}^{-1} \mathrm{~K}^{-1}$ & $\Delta G^{\circ} / \mathrm{kJ} \mathrm{mol}^{-1}$ \\
\hline $\mathrm{MP}_{\text {cellulose }}$ & $-124 \pm 1.1$ & $-369 \pm 3.8$ & $-14 \pm 4.0$ \\
$\mathrm{MP}_{\text {dopamine }}$ & $-166 \pm 1.2$ & $-521 \pm 3.2$ & $-11 \pm 4.5$ \\
$\mathrm{MP}$ & $47 \pm 1.0$ & $186 \pm 2.9$ & $-8 \pm 3.9$
\end{tabular}


Table 5 Langmuir and Freundlich isotherm constants for adsorption of BLA on magnetic nanoparticles as determined from Fig. S1

\begin{tabular}{llll}
\hline Particles & Isotherm & Parameters & Values \\
\hline MP $_{\text {cellulose }}$ & Langmuir & $q_{\text {max }}\left(\mathrm{mg} \mathrm{g}^{-1}\right)$ & $833 \pm 23.31$ \\
& & $K_{\mathrm{L}}\left(\mathrm{mL} \mathrm{mg}^{-1}\right)$ & $12 \pm 1.04$ \\
& $R_{\mathrm{L}}$ & $0.48 \pm 0.01$ \\
& $R^{2}$ & 0.99 \\
& Freundlich & $K_{\mathrm{f}}\left(\mathrm{mL} \mathrm{g}^{-1}\right)$ & $728 \pm 21$ \\
& $1 / n$ & $0.22 \pm 0.02$ \\
$\mathrm{MP}_{\text {dopamine }}$ & Langmuir & $R^{2}$ & 0.98 \\
& & $q_{\max }\left(\mathrm{mg} \mathrm{g}^{-1}\right)$ & $714 \pm 13.12$ \\
& & $K_{\mathrm{L}}\left(\mathrm{mL} \mathrm{mg}^{-1}\right)$ & $14 \pm 0.96$ \\
& $R^{2}$ & $0.15 \pm 0.03$ \\
& Freundlich & $K_{\mathrm{f}}\left(\mathrm{mL} \mathrm{g}^{-1}\right)$ & 0.99 \\
& $1 / n$ & $658 \pm 35$ \\
& & $R^{2}$ & $0.18 \pm 0.01$ \\
& & $q_{\max }\left(\mathrm{mg} \mathrm{g}^{-1}\right)$ & 0.97 \\
& Langmuir & $K_{\mathrm{L}}\left(\mathrm{mL} \mathrm{mg}^{-1}\right)$ & $7.5 \pm 0.21$ \\
& & $R_{\mathrm{L}}$ & $0.17 \pm 0.02$ \\
& & $R^{2}$ & 0.99 \\
& & $K_{\mathrm{f}}\left(\mathrm{mL} \mathrm{g}^{-1}\right)$ & $577 \pm 23$ \\
& Freundlich & $1 / n$ & $0.19 \pm 0.02$ \\
& & $R^{2}$ & 0.93 \\
& &
\end{tabular}

determination of $K_{\mathrm{A}}$ (Table 2). Compared to other reported binding constants of proteins to particles, which are in the order of $10^{6}$ to $10^{8} \mathrm{M}^{-1},{ }^{\mathbf{1 3}, 30,31}$ (Table 3), the binding constant of BLA to $\mathrm{MP}_{\text {cellulose }}$ is strong. Its value is decreasing with increasing temperature due to unreduced adsorption of the protein to the particles. ${ }^{32,33}$ This indicates a static quenching mechanism and decrease in the quantum yield caused by the formation of a non-fluorescent ground state complex. ${ }^{34}$ This is in contrast to naked MP where the value of $K_{\mathrm{A}}$ is increasing with increasing temperature which refers to dynamic quenching mechanism caused by the collisional encounter between the fluorophore and quencher molecules. ${ }^{34}$

The $n$ value decreases in addition with higher temperature due to the decrease of the cooperativity due to conformal change and/or further protein adsorption.

Finally, using eqn (3) and (4)

$$
\ln K_{\mathrm{A}}=-\frac{\Delta H^{\circ}}{R T}+\frac{\Delta S^{\circ}}{R}
$$

Table 6 Förster's theory: determination of Förster critical distance $R_{0}$, the distance between the donor and acceptor $r, J$ a factor describing the overlapping between the emission spectrum of the donor and the absorption spectrum

\begin{tabular}{llll}
\hline Förster parameter & $\mathrm{MP}_{\text {cellulose }}$ & $\mathrm{MP}_{\text {dopamine }}$ & $\mathrm{MP}$ \\
\hline$R_{0}(\mathrm{~nm})$ & $4.5-5.5$ & $3.7-4.5$ & $4.5-5.4$ \\
$r(\mathrm{~nm})$ & $4.2-5.1$ & $4.6-5.5$ & $4.9-5.9$ \\
$J(\lambda)\left(\mathrm{M}^{-1} \mathrm{~cm}^{3}\right)$ & $2.42 \times 10^{-13}$ & $7.73 \times 10^{-14}$ & $2.51 \times 10^{-13}$ \\
$E$ & 0.4099 & 0.2197 & 0.3776 \\
\hline & &
\end{tabular}

with $R$ being the universal gas constant, the thermodynamic parameters $\left(\Delta H^{\circ}\right.$ and $\left(\Delta S^{\circ}\right)$ as well as the Gibbs free energy $\left(\Delta G^{\circ}\right)$ were determined (Table 4). A meaningful relationship between the sign of the thermodynamic parameters and the types of interaction that contribute in ligand-protein binding process was confirmed by Ross and Subramanian in $1981 .^{35}$ According to the enthalpy and entropy changes in the case of $\mathrm{MP}_{\text {cellulose }}$ and $\mathrm{MP}_{\text {dopamine }}$ with $\Delta H^{\circ}<0$ and $\Delta S^{\circ}<0$, the modes of interaction between BLA and the particles are van der Waals interactions and hydrogen bonds, occurring spontaneously $\left(\Delta G^{\circ}<0\right)$. This is in contrast to MP, where hydrophobic forces are believed to be mainly responsible for the interaction of BLA with MPs.

3.2.1 Adsorption isotherms of BLA to $\mathbf{M P}_{\text {cellulose }}$ The high binding constant of $\mathrm{MP}_{\text {cellulose }}$ might be related to the good capacity of the nanoparticles to adsorb BLA. Analyzing the amount of BLA in the solution before and after adsorption at $289 \mathrm{~nm}$ using UV/Vis measurements, allowed determining the adsorption capacity $\left[q_{\mathrm{e}}\left(\mathrm{mg} \mathrm{g}^{-1}\right)\right]$ using eqn (5)

$$
q_{\mathrm{e}}=\frac{\left(C_{0}-C_{\mathrm{e}}\right) V}{W}
$$

where $C_{0}\left(\mathrm{mg} \mathrm{mL}^{-1}\right)$ and $C_{\mathrm{e}}\left(\mathrm{mg} \mathrm{mL}^{-1}\right)$ are the initial and final BLA concentrations, $V(\mathrm{~mL})$ the volume of the solution and $W(\mathrm{~g})$ the weight of adsorbents (magnetic particles).

Assuming the formation of an adsorbate monolayer on the particles, application of the Langmuir adsorption isotherm (eqn (6))

$$
\frac{1}{q_{\mathrm{e}}}=\frac{1}{q_{\max }}+\frac{1}{q_{\max } K_{\mathrm{L}} C_{\mathrm{e}}}
$$
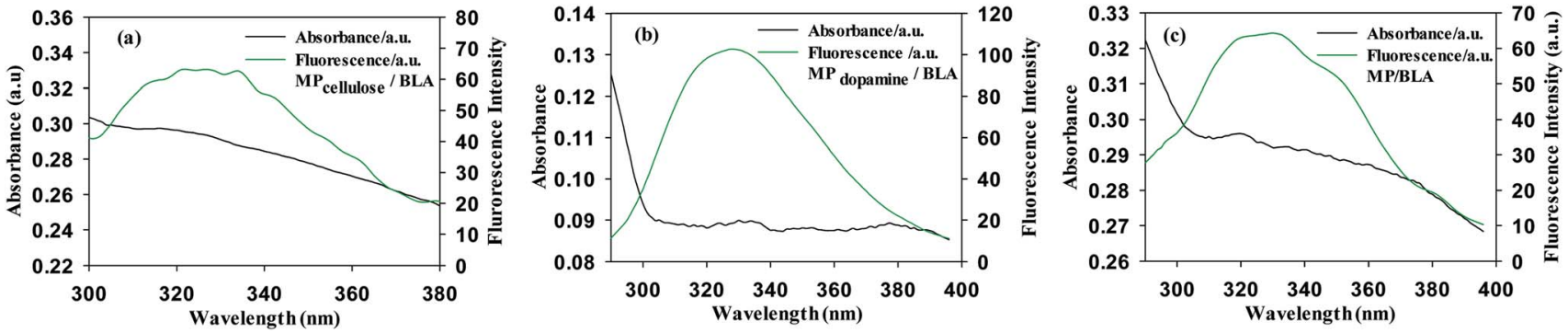

Fig. 3 Emission and absorption spectra of (a) $M P_{\text {cellulose }} / B L A$, (b) $M P_{\text {dopamine }} / B L A$ and (c) MP/BLA, $\lambda_{\text {ex }}=280 \mathrm{~nm}$. 
Table 7 Percentage of secondary structural content of BLA in the absence and presence of magnetic particles

\begin{tabular}{lllll}
\hline Secondary structure & BLA & MP $_{\text {cellulose }} / \mathrm{BLA}$ & MP $_{\text {dopamine }} / \mathrm{BLA}$ & $\mathrm{MP} / \mathrm{BLA}$ \\
\hline$\alpha$-Helix & 22.6 & 24 & 22.2 & 23.1 \\
$\beta$-Sheet & 25.2 & 25 & 26.0 & 25.4 \\
$\beta$-Turn & 17.3 & 17.6 & 17.5 & 17.5 \\
Random coil & 34.8 & 33.4 & 33.9 & 33.7
\end{tabular}

where $q_{\max }$ is maximum monolayer coverage capacity $\left(\mathrm{mg} \mathrm{g}^{-1}\right)$, $C_{\mathrm{e}}\left(\mathrm{mg} \mathrm{mL}^{-1}\right)$ the equilibrium concentration of BLA in the solution and $K_{\mathrm{L}}\left(\mathrm{mL} \mathrm{mg}^{-1}\right)$ is the Langmuir constant, allowed determining $q_{\max }$ and $K_{\mathrm{L}}$ (see ESI, Fig. S1 $\dagger$ ) from the slope and intercept of the Langmuir plot (Table 5).

A plot of $1 / q_{\mathrm{e}} v s .1 / C_{\mathrm{e}}$ allowed determining the equilibrium parameter $R_{\mathrm{L}}$ (eqn (7)) a dimensionless constant referred to as separation factor or equilibrium parameter:

$$
R_{\mathrm{L}}=\frac{1}{1+\left(1+K_{\mathrm{L}} C_{0}\right)}
$$

$R_{\mathrm{L}}>1$ indicates unfavorable adsorption, $0<R_{\mathrm{L}}<1$ favorable and $R_{\mathrm{L}}=0$ irreversible adsorption. The determined $R_{\mathrm{L}}$ values are greater than 0 but less than 1 , indicating that under the Langmuir isotherm model adsorption of BLA onto the particles is favorable. The first assumption of the Langmuir model is monolayer coverage of the adsorbed molecules on the surface. Generally, there is no tendency for protein molecules to adhere to one another and this causes the nanoparticles surface to be saturated with monolayer coverage of protein molecules. Another important assumption of the Langmuir model is non-interacting adsorbent species on the surface. The CD measurements and synchronous fluorescence results provide evidences that the secondary and tertiary structures of the protein were conserved and aggregation or clustering
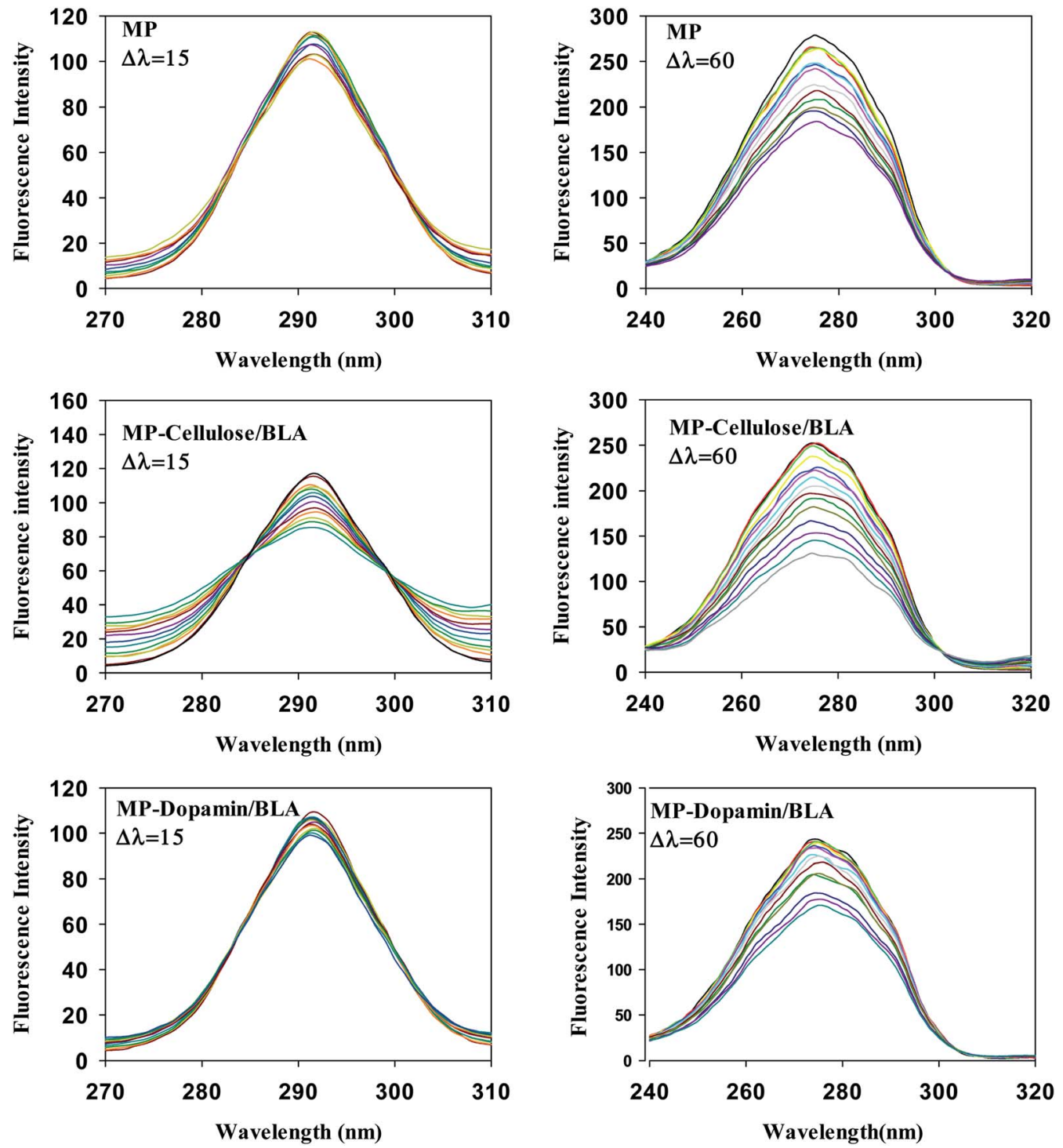

Fig. 4 The effect of the magnetic nanoparticles on the synchronous fluorescence of BLA at $\Delta \lambda=15$ and $\Delta \lambda=60$. [BLA] $=2.5 \mu \mathrm{M}$, [ligands] $=0-$ $30 \mu \mathrm{M}$. 
among the adsorbed BLA molecules on the nanoparticles surface did not take place; hence this assumption of the Langmuir model is satisfied. Though the current results are well fitted to the Langmuir isotherm, but sometimes all the required conditions of this isotherm model for adsorption of proteins on the surface are not satisfied, so it is better to suggest that adsorption data have Langmuir-looking behavior. ${ }^{36}$

3.2.2 Freundlich adsorption isotherm. This model used to describe the adsorption characteristics for the heterogeneous surface which considers multilayer adsorption. The linear form of Freundlich equation is represented by the following equation:

$$
\log Q_{\mathrm{e}}=\log K_{\mathrm{f}}+\frac{1}{n} \log C_{\mathrm{e}}
$$

where $K_{\mathrm{f}}\left(\mathrm{mL} \mathrm{g}^{-1}\right)$ is the Freundlich adsorption isotherm constant relating to the extent of adsorption and $1 / n$ is related to the strength of adsorption in the adsorption process, which varies with the heterogeneity of the material. The slope and intercept of the Freundlich plot of $\log q_{\mathrm{e}} v s . \log C_{\mathrm{e}}$ was used for obtaining the $1 / n$ and $K_{\mathrm{f}}$ values (see ESI, Fig. S1 $\dagger$ ). If the value of $1 / n$ is below one, it indicates a normal adsorption. On the other hand, $1 / n$ being above one indicates cooperative adsorption. The extracted Freundlich parameters are listed in Table 5. As can be seen, the Langmuir-looking model has a slightly better description for the adsorption of BLA molecules on the surface of magnetic particles.

3.2.3 Electrostatic contributions. Salt titration experiments were performed in addition to evaluate the contribution of electrostatic interactions between magnetic nanoparticles and BLA in the process of adsorption. Magnetic particle/ protein solutions were titrated with sodium chloride and the release of BLA through disruption of the electrostatic interaction and recovery of the Trp fluorescence were determined (see ESI, Fig. S2 $\dagger$ ). In the case of $\mathrm{MP}_{\text {cellulose }}$ and $\mathrm{MP}_{\text {dopamine }}$ the recovery of the Trp fluorescence intensity upon increasing the ionic strength was observed, indicating the presence of electrostatic interactions. So the more adsorptive capacity in the $\mathrm{MP}_{\text {cellulose }}$ and $\mathrm{MP}_{\text {dopamine }}$ cases are reasonable due to the contribution of both electrostatic interaction and hydrogen bonding.

\subsection{Energy transfer from the BLA to MPs}

BLA fluorescence quenching in the presence of increasing concentrations of MP could be the result of energy transfer. Fig. 3 shows a spectral overlap between the emission spectrum of BLA and absorption spectrum of the studied magnetic particles. According to the Förster's theory (see ESI $1 \dagger$ ), parameters such as the Förster critical distance $R_{0}, J$ a factor describing the overlapping between the emission spectrum of the donor and the absorption spectrum of the acceptor (particle in our case) and the $r$ value were determined (Table 6). A nonradiative energy transfer occurred with high probability between the magnetic particles and BLA because of the estimated distance values which is on the $2-7 \mathrm{~nm}$ scale.

\subsection{Circular dichroism (CD)}

Circular dichroism (CD) spectroscopy was in addition used to obtain information about eventual protein deactivation. As illustrated in Fig. $\mathrm{S} 3, \uparrow$ the secondary structure of BLA remains intact upon adsorption onto the magnetic particles (Table 7).

\subsection{Conformational investigation by synchronous fluorescence}

The important technique which provides interesting information about the micro region of fluorophore molecules is synchronous fluorescence spectroscopy. It offers information about the molecular environment characteristics such as polarity in the vicinity of the fluorophore molecules. According to the theory of Miller, by taking synchronous spectra at the selected wavelength difference, $\Delta \lambda\left(\lambda_{\mathrm{em}}-\lambda_{\mathrm{ex}}\right)$, the fluorescence spectral properties of tryptophan and tyrosine residues can be separated. When $\Delta \lambda$ is $15 \mathrm{~nm}$ the fluorescence spectrum reflects the emission by tyrosine residue whereas the difference of $60 \mathrm{~nm}$ between excitation and emission wavelengths gives the information about tryptophan residue. ${ }^{37}$ Fig. 4 shows the synchronous spectra of all types of magnetic nanoparticles with

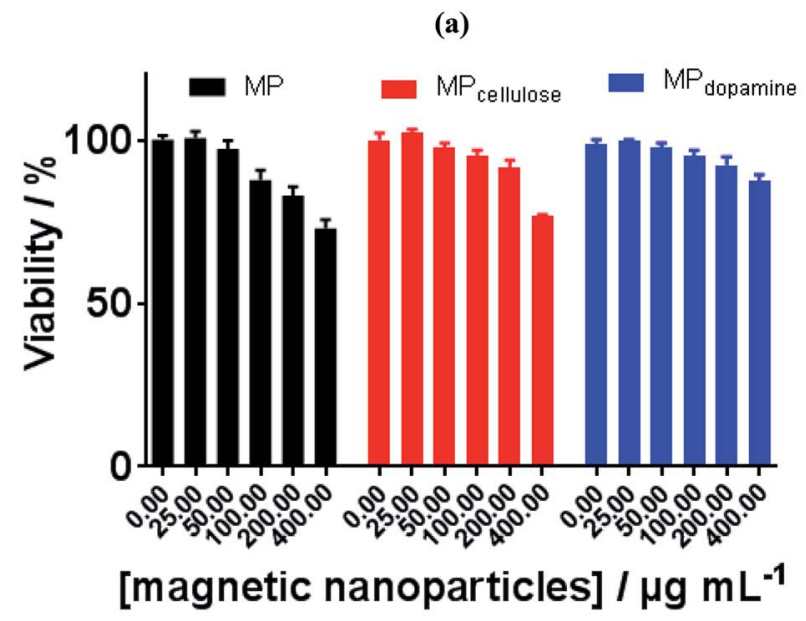

(b)

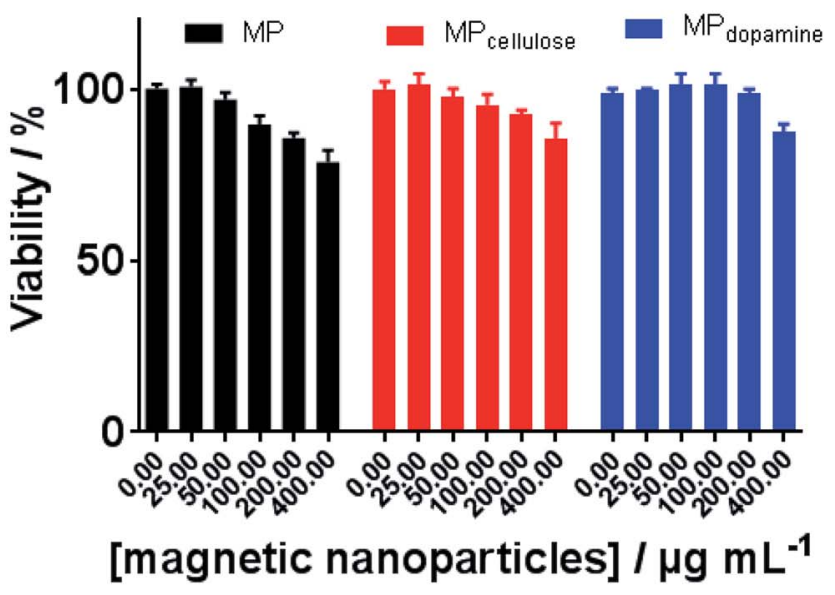

Fig. 5 Cell viability of MP, MP cellulose, and MP dopamine alone (a) and after incubation with BLA (b). 


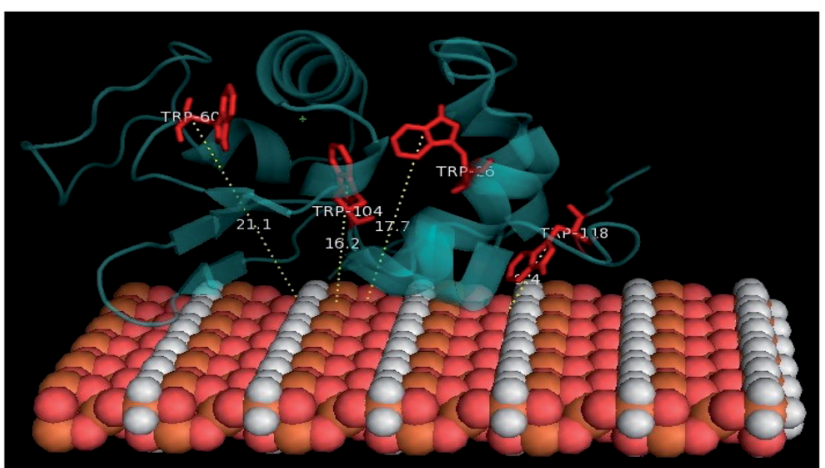

Fig. 6 The calculated distances between MP-sheet and four tryptophans in BLA rendered by PyMol.

BLA at $\Delta \lambda$ of $15 \mathrm{~nm}$ and $60 \mathrm{~nm}$. The extent of the quenching in the case of $\Delta \lambda=60 \mathrm{~nm}$, is greater than that of $\Delta \lambda=15 \mathrm{~nm}$. So, the Trp residues of BLA are at close vicinity of magnetic nanoparticles. In the spectra at $\Delta \lambda=60$ no considerable shift in the $\lambda_{\max }$ was observed upon addition of all types of magnetic nanoparticles. So, it can be verified that the polarity of the micro region of the tryptophan residues does not change in the process of binding.

\subsection{Cell viability}

Toxicity has already become a significant biological issue of MPs, and thus beside the physicochemical investigation of interaction of the considered MPs in the current work with BLA, their toxicities were further studied. The cell toxicity of the MP, $\mathrm{MP}_{\text {dopamine }}$ and $\mathrm{MP}_{\text {cellulose }}$ alone and after incubation with BLA forming $\mathrm{MP} / \mathrm{BLA}$ bioconjugate was established on neuroblastomaxglioma hybrid cell line, NG108-15, widely used in in vitro studies instead of primary-cultured neurons (Fig. 5). Cell viability was assessed by the well-established resazurin assay, which does not suffer from unspecific interaction with magnetic particles. Particles' toxicity was evaluated based on cell viability assessment relative to controls as proposed by Kong et $a .^{38}$ : cell viability $>90 \%$ correlates with non-toxic nanoparticles, cell viability of $60-90 \%$ reveals slight toxicity, cell viability between $30-60 \%$ shows toxic features, and cell viability $<30 \%$ corresponds to severe toxicity. In the absence of BLA, MP is non-toxic up to $50 \mu \mathrm{g} \mathrm{mL}^{-1}$, whereas $\mathrm{MP}_{\text {dopamine }}$ and

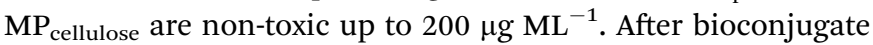
formation with BLA, the cell viability of $100 \mu \mathrm{g} \mathrm{ML} \mathrm{ML}^{-1}$ of MP increased to more than $90 \%$, and for $400 \mu \mathrm{g} \mathrm{mL}^{-1}$ of $\mathrm{MP}_{\text {dopamine }}$ and $\mathrm{MP}_{\text {cellulose }}$, the cell viability increased to more than $80 \%$. The results of cytotoxicity showed that not only coating of magnetic particles with cellulose and dopamine results in increasing the cell viability, but also formation of BLA corona, caused that $\mathrm{MP}_{\text {dopamine }}$ and $\mathrm{MP}_{\text {cellulose }}$ to be non-toxic even at higher concentration. The cell viability results reported so far revealed that the toxicity of bare MPs are higher than for other coated MPs, due to their tendency to adsorb proteins, amino acids, vitamins, and ions causing changes in $\mathrm{pH}$ and composition in cells and cell media. ${ }^{39}$

\subsection{Molecular docking}

Docking studies were finally performed in order to identify the involvement of amino acids in the binding of BLA to the MPs. The five best docked BLA structures with $\mathrm{MP}_{\text {cellulose }}, \mathrm{MP}_{\text {dopamine, }}$ and MP (see ESI, Fig. S4-S6†) indicate the formation of an energetically stable corona coating. The closeness of tryptophan residues, especially Trp118 to MP (Fig. 6), is in agreement with the fluorescence quenching results. There are few reports about the environment of BLA tryptophans. ${ }^{\mathbf{4 0 - 4 2}}$ Based on these few reports Trp-118 is the most exposed tryptophan, while Trp-26 is a buried residue in the protein, harbored in a hydrophobic

Table 8 The total energy and the interface amino acids of various orientations of MP cellulose $_{\text {BLA interaction }}$

\begin{tabular}{|c|c|c|}
\hline Docked pose & Total energy (a.u.) & Amino acids \\
\hline 1 & -668.66 & $\begin{array}{l}\text { Asp14, Leu15, Lys16, Gly17, Tyr18, Gly19, Gly20, } \\
\text { Val21, Ser22, Leu23, pro24, Glu25, Lys93, Lys94, } \\
\text { Ile95, Leu96, Asp97, Lys98, Val99, Gly103, } \\
\text { Ile101, Asn102, Tyr103, His107, CYs111, Ser112, } \\
\text { Leu115, Asp116, Trp118, Leu119 }\end{array}$ \\
\hline 2 & -571.76 & $\begin{array}{l}\text { Lys16, Gly17, Tyr18, Gly19, Gly20, Val21, Ser22, } \\
\text { Lys93, Lys94, Ile95, Leu96, Asp97, Lys98, Val99, } \\
\text { Gly103, Ile101, Asn102 }\end{array}$ \\
\hline 3 & -559.92 & $\begin{array}{l}\text { Asp14, Leu15, Lys16, Gly17, Tyr18, Gly19, Gly20, } \\
\text { Val21, Ser22, Leu23, pro24, Glu25, Lys93, Lys94, } \\
\text { Ile95, Tyr103, His107, CYs111, Ser112, Leu115, } \\
\text { Asp116, Trp118, Leu119 }\end{array}$ \\
\hline 4 & -545.77 & $\begin{array}{l}\text { Lys16, Gly17, Tyr18, Gly19, Gly20, Val21, Ser22, } \\
\text { Leu23, pro24, Glu25, Lys93, Lys94, Ile95, Tyr103, } \\
\text { His107, CYs111, Ser112, Leu115, Asp116, } \\
\text { Trp118 }\end{array}$ \\
\hline 5 & -538.67 & $\begin{array}{l}\text { pro24, Glu25, Lys93, Lys94, Ile95, Tyr103, } \\
\text { His107, CYs111, Ser112, Leu115, Asp116, } \\
\text { Trp118, Leu119 }\end{array}$ \\
\hline
\end{tabular}


Table 9 The parameters of the five stable MPcellulose/BLA complex, as obtained by molecular docking. The calculated distances between the interface interactive amino acids and the $\mathrm{MP}_{\text {cellulose }}$-sheet and the types of bindings which contributed in the binding site

\begin{tabular}{|c|c|c|c|c|}
\hline \multirow[t]{11}{*}{ Pose 1} & Lys16 & 2.36 & Hydrogen bond & Conventional \\
\hline & Tyr18 & 2.74 & Hydrogen bond & Conventional \\
\hline & Asp14 & 2.35 & Hydrogen bond & Conventional \\
\hline & Glu25 & 2.73 & Hydrogen bond & Conventional \\
\hline & Gly19 & 2.66 & Hydrogen bond & Conventional \\
\hline & Sr112 & 2.38 & Hydrogen bond & Carbon \\
\hline & Lys16 & 5.18 & Hydrophobic & Alkyl \\
\hline & Val21 & 4.61 & Hydrophobic & Alkyl \\
\hline & Ile101 & 4.31 & Hydrophobic & Alkyl \\
\hline & Tyr18 & 4.97 & Hydrophobic & Pi-alkyl \\
\hline & His32 & 2.77 & Hydrogen bond & Conventional \\
\hline & His107 & 3.77 & Hydrogen bond & Carbon \\
\hline & Asn102 & 2.16 & Hydrogen bond & Conventional \\
\hline \multirow[t]{2}{*}{ Pose 5} & Ser112 & 2.15 & Hydrogen bond & Conventional \\
\hline & Lys114 & 1.89 & Hydrogen bond & Conventional \\
\hline
\end{tabular}

pocket. Trp-60 and Trp-104 are close to each other; Trp-60 is largely solvent excluded, while Trp-104 is partially solvent inaccessible. The tail conformation of Trp-118 determines its position either in a buried or exposed state. The same results

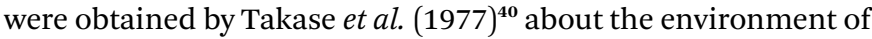
BLA tryptophans. They suggested that Trp-26 is solvent inaccessible residues and located in the nonpolar interior of the protein matrix. Trp-60 is almost shielded from the solvent. Based on their results a cleft-like region which contains Trp-60 and either Trp-104 or Trp-118 exists in the protein molecule. Either Trp-104 or Trp-118 is largely solvent accessible to solvent or located on the molecule surface. ${ }^{40-42}$

It seems that Trp-118 is more likely attainable to magnetic particles because it is the most exposed tryptophan. Trp-104 is the most exposed tryptophan, so the possibility of binding the ligands to this residue also exists. Trp-26 and Trp60 are buried in the interior of the protein and are inaccessible to the solvent. Docking studies results can help to better understanding of the details of the contribution of tryptophans in the reduction of fluorescence intensity of BLA during the binding process. The CD spectroscopy illustrated no altering in the second structure of protein in the process of binding and by the synchronous fluorescence results no polarity altering around the tryptophan residues was observed, so the hydrophobic patches of protein are not exposed to solvent and the tryptophans like Trp-26 and Trp104 which are buried in their pocket will still be hided from the solvent. By docking investigation, the closeness of magnetic particles to Trp-118 is confirmed. It seems there is no penetration of BLA on the magnetic particles. So the protein slightly attaches to the magnetic particle and consequently forming the corona. Trp-118 has the capability of being the key chromophore which is quenched by quencher molecules called magnetic particle in this work.

The PyMol method was used for calculating the distance of four tryptophan residues (Trp-26, Trp-60, Trp-104 and Trp118) to magnetic particles sheets. These distances are comparable with experimental distances from FRET calculation (Tables 8 and 9).

\section{Conclusion}

The strong binding affinities between non-coated magnetic nanoparticles (MP) or magnetite nanoparticles stabilized with different dopamine ligands ( $\left.\mathrm{MP}_{\text {dopamine }}\right)$ and cellulose $\left(\mathrm{MP}_{\text {cellulose}}\right)$ and bovine alpha lactalbumin (BLA) was concluded from the zeta potential analysis, UV-Vis spectroscopy, and steady state fluorescence. Coating the magnetic particles with cellulose and dopamine leads to stronger binding affinities to BLA which is observable from capacity adsorption determination experiment and also can be related to the electrostatic interactions contribution from the salt titration experiment in addition to the hydrogen bonding contribution deduced from the thermodynamic parameters. The involved amino acid residues of BLA in the process of adsorption on the surface of magnetic particles were identified by docking calculation and the Trp-118 was evaluated as key fluorophore. A non-radiative energy transfer with high probability between these particles and BLA was confirmed because of the short distances between MP-sheet and four tryptophan residues in BLA calculated by FRET experiment and PyMol calculations. The cell viability results showed that formation of bioconjugate with BLA causes an increase in the non-toxic range of the considered MP in this project. No altering in the major roles of BLA in transport of the drugs/bioactive compounds is expected because 
of the no conformal change of the protein in the process of binding to the magnetic nanoparticles. This important characteristic in addition to extremely strong binding affinity makes these particles new model nanostructures for nanomedicine orientated applications.

\section{Conflicts of interest}

There are no conflicts to declare.

\section{Acknowledgements}

Financial support from Iran National Science Foundation (INSF) (grant number 95841679), Institute for Advanced Studies in Basic Sciences (IASBS), the Centre National de la Recherche Scientifique (CNRS), the University of Lille, the Hauts-de-France region, and the CPER "Photonics for Society" are acknowledged. The Fonds Européen de Développement Régional (FEDER), CNRS, Région Nord Pas-de-Calais and Ministère de l'Education Nationale de l'Enseignement Supérieur et de la Recherche are acknowledged for funding of XPS/LEIS/ToF-SIMS spectrometers within the Pôle Régional d'Analyses de Surface.

\section{References}

1 M. Mahmoudi, I. Lynch, M. R. Ejtehadi, M. P. Monopoli, F. B. Bombelli and S. Laurent, Protein-nanoparticle interactions: opportunities and challenges, Chem. Rev., 2011, 111, 5610-5637.

2 M. Lundqvist, J. Stigler, G. Elia, I. Lynch, T. Cedervall and K. A. Dawson, Nanoparticle size and surface properties determine the protein corona with possible implications for biological impacts, Proc. Natl. Acad. Sci. U. S. A., 2008, 105, 14265-14270.

3 S. Tenzer, D. Docter, J. Kuharev, A. Musyanovych, V. Fetz, R. Hecht, F. Schlenk, D. Fischer, K. Kiouptsi, C. Reinhardt, K. Landfester, H. Schild, M. Maskos, S. K. Knauer and R. H. Stauber, Rapid formation of plasma protein corona critically affects nanoparticle pathophysiology, Nat. Nanotechnol., 2013, 8, 772.

4 R. Li, R. Chen, P. Chen, Y. Wen, P. C. Ke and S. S. Cho, Computational and experimental characterizations of silver nanoparticle-apolipoprotein biocorona, J. Phys. Chem. B, 2013, 117, 13451-13456.

5 B. K. Paul, K. Bhattacharjee, S. Bose and N. Guchhait, A spectroscopic investigation on the interaction of a magnetic ferrofluid with a model plasma protein: effect on the conformation and activity of the protein, Phys. Chem. Chem. Phys., 2012, 14, 15482-15493.

6 B. Wang, S. A. Seabrook, P. Nedumpully-Govindan, P. Chen, H. Yin, L. Waddington, V. C. Epa, D. A. Winkler, J. K. Kirby, F. Ding and P. C. Ke, Thermostability and reversibility of silver nanoparticle-protein binding, Phys. Chem. Chem. Phys., 2015, 17, 1728-1739.

7 C. Carnovale, G. Bryant, R. Shukla and V. Bansal, Impact of nanogold morphology on interactions with human serum, Phys. Chem. Chem. Phys., 2018, 20, 29558-29565.
8 J. Ashby, S. Pan and W. Zhong, Size and Surface Functionalization of Iron Oxide Nanoparticles Influence the Composition and Dynamic Nature of Their Protein Corona, ACS Appl. Mater. Interfaces, 2014, 6, 15412-15419.

9 V. Hirsch, C. Kinnear, M. Moniatte, B. Rothen-Rutishauser, M. J. D. Clift and A. Fink, Surface charge of polymer coated SPIONs influences the serum protein adsorption, colloidal stability and subsequent cell interaction in vitro, Nanoscale, 2013, 5, 3723-3732.

10 A. Jedlovszky-Hajdú, F. B. Bombelli, M. P. Monopoli, E. Tombácz and K. A. Dawson, Surface Coatings Shape the Protein Corona of SPIONs with Relevance to Their Application in Vivo, Langmuir, 2012, 28, 14983-14991.

11 F. M. Kievit and M. Zhang, Surface Engineering of Iron Oxide Nanoparticles for Targeted Cancer Therapy, Acc. Chem. Res., 2011, 44, 853-862.

12 L. Lartigue, C. Wilhelm, J. Servais, C. Factor, A. Dencausse, J.-C. Bacri, N. Luciani and F. Gazeau, Nanomagnetic Sensing of Blood Plasma Protein Interactions with Iron Oxide Nanoparticles: Impact on Macrophage Uptake, ACS Nano, 2012, 6, 2665-2678.

13 S. Liu, Y. Han, R. Qiao, J. Zeng, Q. Jia, Y. Wang and M. Gao, Investigations on the Interactions between Plasma Proteins and Magnetic Iron Oxide Nanoparticles with Different Surface Modifications, J. Phys. Chem. C, 2010, 114, 2127021276.

14 U. Sakulkhu, M. Mahmoudi, L. Maurizi, G. Coullerez, M. Hofmann-Amtenbrink, M. Vries, M. Motazacker, F. Rezaee and H. Hofmann, Significance of surface charge and shell material of superparamagnetic iron oxide nanoparticle (SPION) based core/shell nanoparticles on the composition of the protein corona, Biomater. Sci., 2015, 3, 265-278.

15 A. A. Shemetov, I. Nabiev and A. Sukhanova, Molecular interaction of proteins and peptides with nanoparticles, ACS Nano, 2012, 6, 4585-4602.

16 E. A. Permyakov and L. J. Berliner, $\alpha$-Lactalbumin: structure and function, FEBS Lett., 2000, 473, 269-274.

17 S. M. Lystvet, S. Volden, Ø. Halskau and W. R. Glomm, Immobilization onto gold nanoparticles alters $\alpha$ lactalbumin interaction with pure and mixed phospholipid monolayers, Soft Matter, 2011, 7, 11501-11509.

18 M. Mazur, A. Barras, V. Kuncser, A. Galatanu, V. Zaitzev, K. V. Turcheniuk, P. Woisel, J. Lyskawa, W. Laure, A. Siriwardena, R. Boukherroub and S. Szunerits, Iron oxide magnetic nanoparticles with versatile surface functions based on dopamine anchors, Nanoscale, 2013, 5, 2692-2702.

19 F. Halouane, R. Jijie, D. Meziane, C. Li, S. K. Singh, J. Bouckaert, J. Jurazek, S. Kurungot, A. Barras, M. Li, R. Boukherroub and S. Szunerits, Selective isolation and eradication of $E$. coli associated with urinary tract infections using anti-fimbrial modified magnetic reduced graphene oxide nanoheaters, J. Mater. Chem. B, 2017, 5, 8133-8142.

20 M. S. Ali, M. Altaf and H. A. Al-Lohedan, Green synthesis of biogenic silver nanoparticles using Solanum tuberosum 
extract and their interaction with human serum albumin: Evidence of "corona" formation through a multispectroscopic and molecular docking analysis, $J$. Photochem. Photobiol., B, 2017, 173, 108-119.

21 S. Khan, A. Gupta and C. K. Nandi, Controlling the Fate of Protein Corona by Tuning Surface Properties of Nanoparticles, J. Phys. Chem. Lett., 2013, 4, 3747-3752.

22 K. Turcheniuk, A. V. Tarasevych, V. P. Kukhar, R. Boukherroub and S. Szunerits, Recent advances in surface chemistry strategies for the fabrication of functional iron oxide based magnetic nanoparticles, Nanoscale, 2013, 5, 10729-10752.

23 M. Mahmoudi, S. Sant, B. Wang, S. Laurent and T. Sen, Superparamagnetic iron oxide nanoparticles (SPIONS): development, surface modification and applications in chemotherapy, Adv. Drug Delivery Rev., 2011, 63, 24-46.

24 G. Kandasamy and D. Maity, Recent advances in superparamagnetic iron oxide nanoparticles (SPIONs) for in vitro and in vivo cancer nanotheranostics, Int. J. Pharm., 2015, 496, 191-218.

25 J. Lodhia, G. Mandarano, N. Ferris, P. Eu and S. Cowell, Development and use of iron oxide nanoparticles (Part 1): synthesis of iron oxide nanoparticles for MRI, Biomed. Imaging Intervention J., 2010, 6, e12.

26 F. Halouane, Y. Oz, D. Meziane, A. Barras, J. Juraszek, S. K. Singh, S. Kurungot, P. K. Shaw, R. Sanyal, R. Boukherroub, A. Sanyal and S. Szunerits, Magnetic reduced graphene oxide loaded hydrogels: highly versatile and efficient adsorbents for dyes and selective $\mathrm{Cr}(\mathrm{VI})$ ions removal, J. Colloid Interface Sci., 2017, 507, 360-369.

27 E. Kaiser, R. L. Colescott, C. D. Bossinger and P. I. Cook, Color test for detection of free terminal amino groups in the solid-phase synthesis of peptides, Anal. Biochem., 1970, 34, 595-598.

28 R. A. Bini, R. F. C. Marques, F. J. Santos, J. A. Chaker and M. Jafelicci, Synthesis and functionalization of magnetite nanoparticles with different amino-functional alkoxysilanes, J. Magn. Magn. Mater., 2012, 324, 534-539.

29 W. R. Ware, Oxygen quenching of fluorescence in solution: an experimental study of the diffusion process, J. Phys. Chem., 1962, 66, 455-458.

30 Q. Yang, J. Liang and H. Han, Probing the Interaction of Magnetic Iron Oxide Nanoparticles with Bovine Serum Albumin by Spectroscopic Techniques, J. Phys. Chem. B, 2009, 113, 10454-10458.
31 B.-F. Pan, F. Gao and L.-M. Ao, Investigation of interactions between dendrimer-coated magnetite nanoparticles and bovine serum albumin, J. Magn. Magn. Mater., 2005, 293, 252-258.

32 F. Mohammadi, A. Sahraei, C. Li, A. Haustrate, V. y. Lehen'kyi, A. Barras, R. Boukherroub and S. Szunerits, Interaction of Human $\alpha$-1-Acid Glycoprotein (AGP) with Citrate-Stabilized Gold Nanoparticles: Formation of Unexpectedly Strong Binding Events, J. Phys. Chem. C, 2019, 123, 5073-5083.

33 M. Mahmoudi, S. E. Lohse, C. J. Murphy, A. Fathizadeh, A. Montazeri and K. S. Suslick, Variation of protein corona composition of gold nanoparticles following plasmonic heating, Nano Lett., 2014, 14, 6-12.

34 J. R. Lacowicz, Principles of Fluorescence Spectroscopy, New York, 2nd edn, 1999.

35 P. D. Ross and S. Subramanian, Thermodynamics of protein association reactions: forces contributing to stability, Biochemistry, 1981, 20, 3096-3102.

36 R. A. Latour, The Langmuir isotherm: a commonly applied but misleading approach for the analysis of protein adsorption behavior, J. Biomed. Mater. Res., Part A, 2015, 103, 949-958.

37 I. L. Vekshin, Separation of the tyrosine and tryptophan components of fluorescence using synchronous scanning method, 1996, vol. 41.

38 N. Kong, T. Jiang, Z. Zhou and J. Fu, Cytotoxicity of polymerized resin cements on human dental pulp cells in vitro, Dent. Mater., 2009, 25, 1371-1375.

39 M. Mahmoudi, S. Laurent, M. A. Shokrgozar and M. Hosseinkhani, Toxicity evaluations of superparamagnetic iron oxide nanoparticles: cell "vision" versus physicochemical properties of nanoparticles, ACS Nano, 2011, 5, 7263-7276.

40 K. Takase, R. Niki and S. Arima, Environment of Tryptophan Residues in $\alpha$-Lactalbumin, J. Biochem., 1978, 83, 371-378.

41 W. J. Browne, A. C. T. North, D. C. Phillips, K. Brew, T. C. Vanaman and R. L. Hill, A possible threedimensional structure of bovine $\alpha$-lactalbumin based on that of hen's egg-white lysozyme, J. Mol. Biol., 1969, 42, 6586.

42 P. K. Warme, F. A. Momany, S. V. Rumball, R. W. Tuttle and H. A. Scheraga, Computation of structures of homologous proteins. .alpha.-lactalbumin from lysozyme, Biochemistry, 1974, 13, 768-782. 